DOE/NASA CR 150536

\title{
INSTALLATION PACKAGE FOR AIR FLAT PLATE COLLFCTOR
}

Prepared from documents furnished by

Life Sciences Engineering

Route 1, Box 746

Morrison, CO 80465

Under Contract NAS8-32261 with

National Aeronautics and Space Administration

George C. Marshall Space Flight Center, Alabama 35812

for the Department of Energy

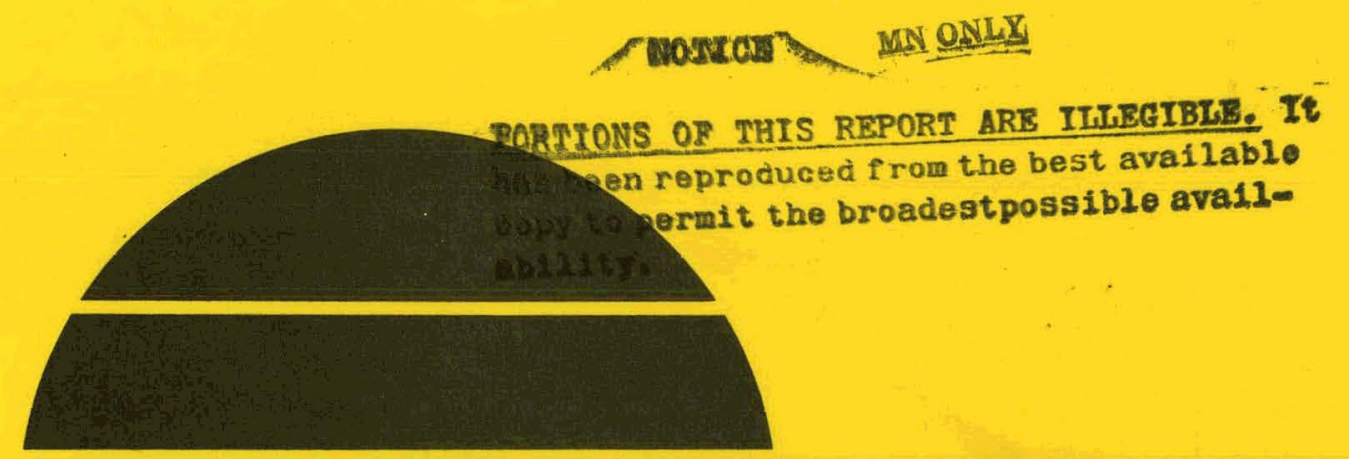

\section{U.S. Department of Energy}




\section{DISCLAIMER}

This report was prepared as an account of work sponsored by an agency of the United States Government. Neither the United States Government nor any agency Thereof, nor any of their employees, makes any warranty, express or implied, or assumes any legal liability or responsibility for the accuracy, completeness, or usefulness of any information, apparatus, product, or process disclosed, or represents that its use would not infringe privately owned rights. Reference herein to any specific commercial product, process, or service by trade name, trademark, manufacturer, or otherwise does not necessarily constitute or imply its endorsement, recommendation, or favoring by the United States Government or any agency thereof. The views and opinions of authors expressed herein do not necessarily state or reflect those of the United States Government or any agency thereof. 


\section{DISCLAIMER}

Portions of this document may be illegible in electronic image products. Images are produced from the best available original document. 
This report was prepared to document work sponsored by the United States Government. Nelther the United States nor 1ts agents the Unfted States Department of Energy, the United States National Aeronautics and Space Administration, nor any federal employees, nor any of their contractors, subcontractors or their employees, make any warranty, express or 1mplied, or assume any legal liability or responsibllity for the accuracy, completeness, or usefuiness of any information, apparatus, product or process disclosed, or represent that 1ts use would not infringe privately owned rights. 
TECHNICAL REPORT ST ANDARD TITLE PAGE

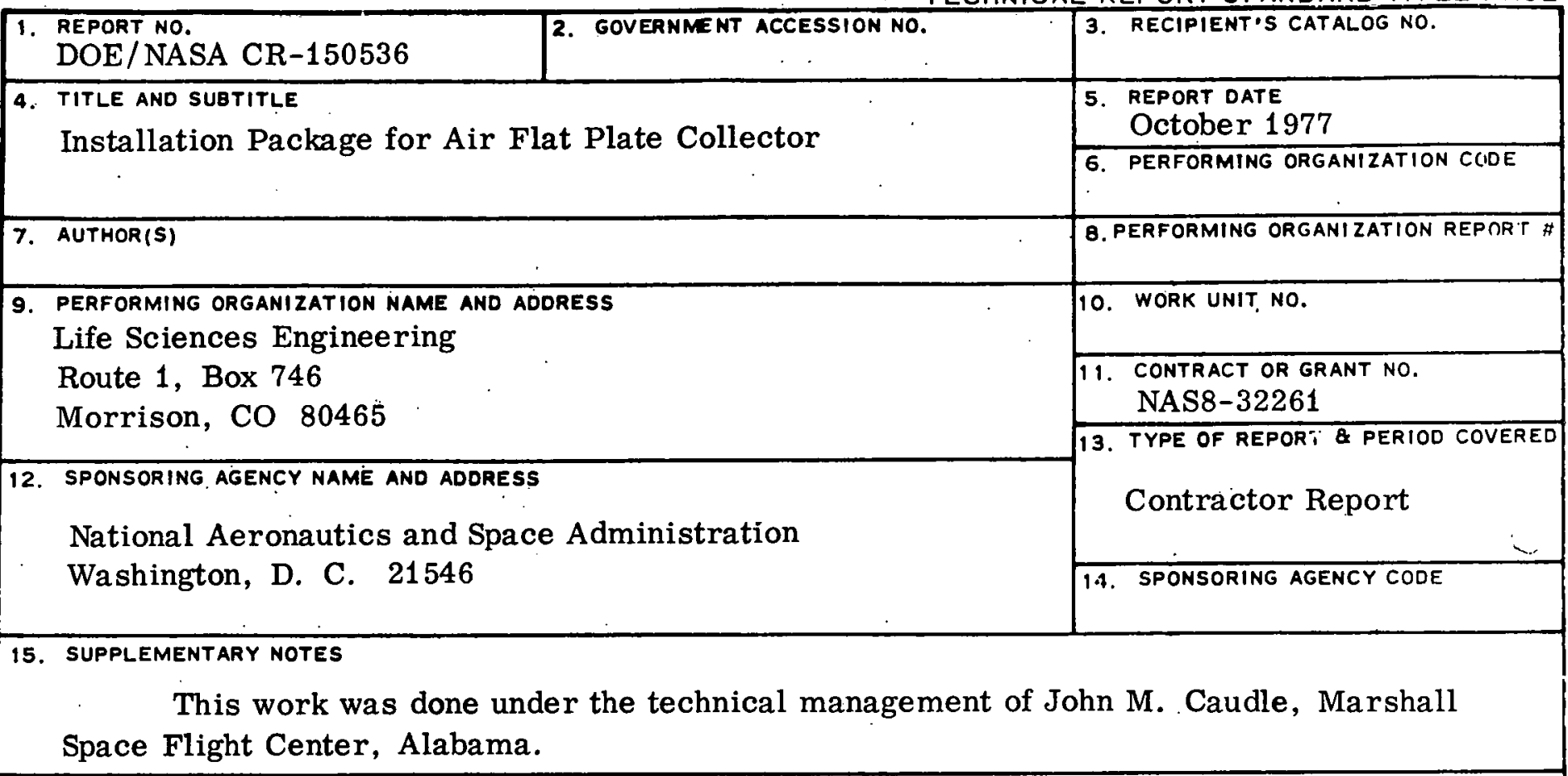

16. ABSTRACT

Life Sciences Engineering, under Contract NAS8-32261, developed the Solar II Air Flat Plate Collector, Model SC4X8, under the direction of the National Aeronautics and Space Administration.

The Solar II dimensions are 4 feet by 8 feet by two and $1 / 2$ inches. The collector weighs 130 pounds and has an effective solar collection area (aperture) of over 29. 5 square feet. This area represents 95 percent of the total surface of the collector.

The Installation, Operation and Maintenance Manual, Safety Hazard Analysis, Special Handling Instructions, Materials List, Installation Concept Drawings, Warranty and Certification Statement are included in the installation package. 
THIS PAGE

\section{WAS INTENTIONALLY LEFT BLANK}




\section{TABLE OF CONTENTS}

Warranty and Certification Statement

Special Handling Instructions 3

Safety Hazard Analysis $\quad$ • 5

Installation, Operation and Maintenance Manual _. 9

Materials List and Installation Concepts Drawing SC4X8106 20

This report was prepared as an account of work
spansored by the United States Governsent. Neither the
United States nor the United States Department of
Energy, nor any of their employees, nor any of their
contractors, subcontractors, or their employees, makes
any warranty, express or implied, or assumes any legal
liahility nr resoonsibility for the accuracy, completeness
or usefulness of any information, apparatus, product or
process disclosad, or represents that its use would not
infsinge privately owned rights.

process disclosed, or represents that its use would not

inf jinge privately owned rights. 


\section{SECTION I}

WARRANTY AND CERTIFICATION STATEMENT 
The Solar II Collector is warranted for 1 year from time of delivery. This warranty covers manufacturing craftsmanship and mormal environment conditions. It does not cover instaliation mishandling or wilful damage: If the collector was purchased without glass from the factory, the local distributor/subcontractor shall warrant the glass for breakage and leakage for 1 year. In the event of a fallure, a replacement component will be supplied for the failed component.

\section{CEHI'IF ICATION S'LA'CL'LUE'N'T}

The Solar II, Air Flat Plate Collector, was tested for operational performance and structrual conformance to specifications directed by the National Aeronautics and space Adininistration. The design and structure of the collector are consistant with applicable national standards. The solar II Collector successfully passed all tests and was evaluated as efficient and safe for public use.
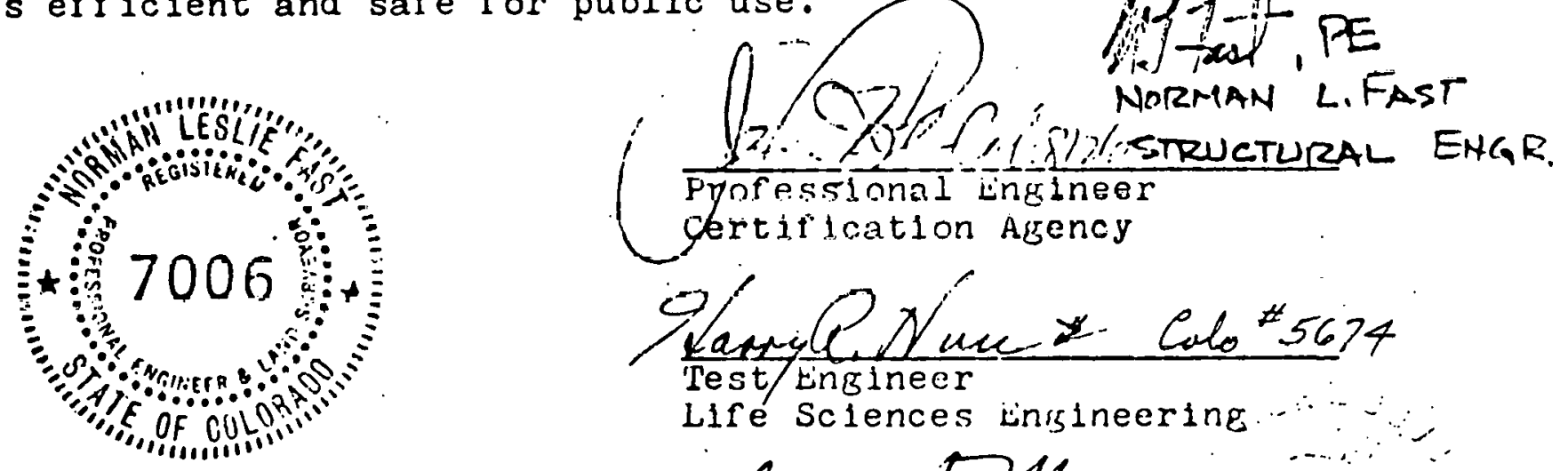

Life Sciences insineering

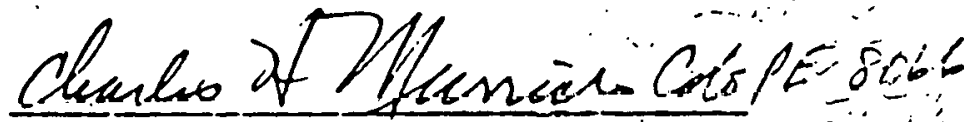

Test virector

Life sclencop lingineering

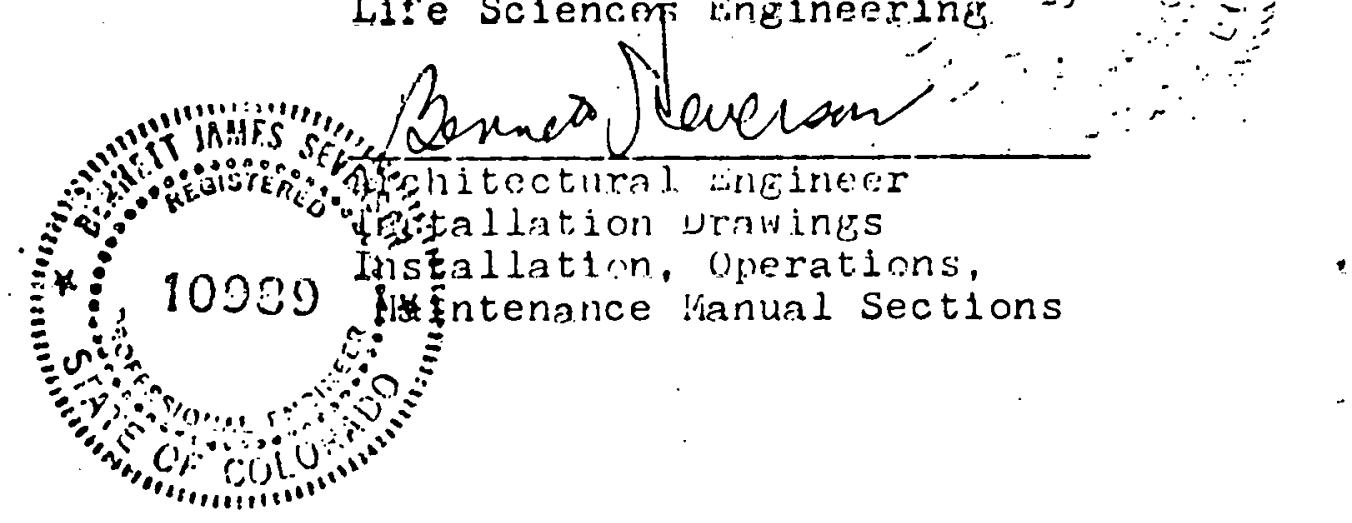




\section{SECTION II}

SPECIAL HANDLING INSTRUCTIONS 


\section{SPECIAL HANDLING INSTRUCTIONS}

1. Procedure for removing the Solar II Collectors from this shipping container.

1.1 This shipping container is made with 8 plywood, triangular corners. Four of these corners are nailed down on one side. On the other side, the corners are screwed down.

1.2. To remove the collectors, place the shipping container with the screw side up. Remove the 4 small screws in the corner triangles and screws holding down the three cross braces. DO NOT REMOVE THE LARGE MACHINE BOLTS (6) which are located inside the screws; one in each corner triangle and one in each end of the center cross brace.

1. 3 Two men are needed to lift the plywood corners with the collector attached. With one man at each end holding the plywood triangles, gently lift the collector up and out. Place the collector with the plywood side down on some $2 \times 4$ 's.

1. 4 Remove the cardboard cover by removing the duct tape.

1. 5 To remove the plywood back support, remove the 6 machine bolts and the collector can be lifted free. The duct tape holding the Tedlar frame and plenum chamber opening may be removed at any time. However, it is recommended that the tape be left on until the collector is to be pul in uperation or test.

1.6 To remove the second collector in the shipping case, place the case on a table where the 6 machine bolts may be removed from underneath. It $m$ ay be necessary for a second $m$ an to hold the nut while the first man removes the bolt.

1.7 When all 6 machine bolts are removed, two men are needed to lift the collector from the case. The plywood back support is pushed up at each end gently until the collector is raised where the men ran get a good grip on the ends of the collector.

CAUTION: DO NOT LIFT THE COLLECTOR BY THE TEDLAR FRAME ALONE. LIFT THE ENTIRE COLLECTOR.

1. 8 The collector should be placed with the Tedlar side up. The cardboard covering the Tedlar may be removed as described in step 1.5. 


\section{SECTION III}

SAFETY HAZARD ANALYSIS 
1. Scope

1.1 Purpose

The purpose of this report is to identify and evaluate significant hazards to the installation crew, resident occupants and visitors.

1.2 Scope

This report presents an assessment of hazards peculiar to this equipment.

The hazards have been identified and categorized. The possible causes and effects have been listed, together with the methods or safeguards required to control or limit the hazard. This analysis does not consider facility or manufacturing features that are required to be made safe under the local codes and regulations.

1.3 Summary

The Hazards Analysis identified no potentially catastrophic hazards and one critical hazard. A catastrophic hazard (Category 1) is one in which death or severe injury to personnel or system loss can occur. A critical hazard (Category 2) is one which could result in personnel injury or cause major damage. 
ITEM NONENCLATURE OF

NO. HARDWARE/ACTIVITY

1

Solar Panel

Assembly
POTENT IAL/ INHERENT HAZARD

CAUSES AND EFFECTS

1. Large areas of dielectric (Tedlar) surface exposed to sky could build up sufficlent static charge to act as flat plate capacitance attractor for lightning. Large amounts of metal in frames could also attract lightning.

2. Aluminum frame of panels will conduct stagnation temperatures to surrounding structure if forced convection air flow is inhibited. High stagnation temp. ( $\left.500^{\circ} \cdot F\right)$ could cause local charing or combustion.

3. Toxic outgassing of materials could have debill tating effect on residents
HAZARD PROPOSED METHOD OF HAZARD

CONTROL OR ELIMINATION

CATEGORY

2 Installation will require

marginal electrical busing of panel assemblies together and to ground per standards and codes for locality

marginal 2

Installation will provide for adequate insulation between panel assembly frame and surrounding struc ture.

3

marginal assembly shall not produce toxic or noxious products when exposed to expected temperature.

\section{REMARKS}

Lightning rods may be required by code in areas of high strike potential (ie. Colorado Springs) 
ITEM NOMENCLATURE OF HARDWARE/ACT IV ITY

Installation of Solar Panel Assembly to Supporting Structure
POTENTIAL/INHERENT HAZARD CAUSES AND EFFECTS

1. Installation personnel could be burned by hot frame or panel when handling.

2. Large panel assemblies $(4 \times 8 \mathrm{ft}$.$) will be heavy$ (100 lbs.) and act as salls in wind. Above ground installations present potential for severe injurj to personnel by being blown off o: by dropping panel on self or another.

3. Improper sealing of panel/. supporting struc ture could result in water leaks.
HAZARD

CATEGORY

PROPOSED METHOD OF HAZARD

CONTROL OR. ELIMINATION

3 Personnel should wear gloves negligible whenever working around exposed panel frames. Panel storage prior to installation should be in a shady area. Panels should be transported wi th collector face away from direct sunlight.

2 Installation should be

critical designed to maximize use of lifting apparatus

3

negliglble

Installation manual will

recommend froper installation

techniques/requi rements.
REMARKS

REMARKS

$\infty$ 
SECTION IV

INSTALLATION, OPERATION AND MAINTENANCE MANUAL 
INSTALLATION, OPESATION INU MAIINENAINCL MANUAL

1." Installatilon

SHC-3070 Rev i

Introduction

Instaliation of the Solar II. Air Flat Plate Collector is a 4 step operation conslsting of hoof Preparation, Collector Preparation, Collector Installation and Closing Up. The solar II collector is shipped normally without glass or insulation to save shipping costs." Glass and Insulation welgh more than two thirds of the total collector weight. Hence to save costs, the installer can purchase the glass and insulation locally. A List of Materials at the end of this manual supplies the necessary detalls.

\subsection{Roof Preparation}

As shown in the installation drawings, the roof must have roughing holes cut in the sheathing. The holes should be a minimum of $2 \frac{1}{2} n$ to 3" by 45" for the plenum/ducting connections. For new construction, just instaling the sheathing that will be under the collectors will provide more room for making connections. If the roof has 24" o.c. rafters, do not cut them, but notify the factory in your order so that air blocks will be installed free of charge. Long1turtinal supports made of $2 \times 4^{\prime} \mathrm{s}, 8^{\prime}$ long, and laid flat, must be centered over each rafter to support the side sections of the collectors. It is important that these supports be nalled to the. sheathing directiy over the rafters to support and distribute the collector welght. If rafters are 1rregular (bowed or warped), use a wider support board such as a 2x6" support. Additional rafters may have to be installed.

After the $2 \times 4$ supports are completed. Install lion insulation with an 
$\mathrm{H}$ value of 9 or better between the supports and the rough openings. Board type insulation is recominended.

\subsection{Collector Preparation}

The Solar. II Collector has 'built in' end connectors. Sleave connectors to connect the collector to the ducting/plenum should be installed on the ground. Sleave Connectors may be purchased from Life sciences Lnglneering or made by the installer. The sleave connector fits over the sind lonnector and is. riveted in place. All connections should be caulked with standard air conditioning caulking.

\subsubsection{Glazingr Instaliation}

If the Solar II is purchased without glass, glass should be purchased locally and installed prior to installation. Carefully reinove the Tedlar frame using a rubber mallet and a piec of $1 / 8$ " angle aluminum to tap the frame loose from under the H-Bar... Insert the sillcone rubber U-channel on the $46 \frac{1}{2} "$ edge of the glass. Gently push the glass with U-channel attached into the H-Bar for a tight fit. With suction cups attached to the glass, gently lower the gliss into position. The slass should have a $5 / 32$ " space around the 3 outside edges. Force Low Corning 732 S111cone Adhesive into this 5/32" space and allow to cure. After curingl hour, put a covering layer of 732 from $3 / 32 "$ over the glass to the frame edges. Then allow the 732 to cure over night. "The redlar frame ray ve re-installed at this time or after installation.

\subsection{Collector Installation}

After completing steps 1.1 and 1.2 , the collector is ready for 
Installation. Installers should wear gloves during installation as collectors standing in the sun become too hot.to hold. They should be kept in the shade until ready for installation.

Installation is a 2 man process due to the size and weight (1301bs.) of the collectors. A holsting device is recommended to position the collector over the prepared location and lower it into position. Make sure that the collectors are evenly spaced between the rafters which can be seen through the rough openings. Spacing between coilectors in parallel is $7 / 8 "$ at the H-Bar level, on the sides. Drill holes in the $2 \times 4 "$ supports for the aluminum round head \#10 screws. that go through the mounting brackets to hold the collector. Use aiumInum washers under the screw head. Lo not tighten down fully as it is necessary to allow some panel movement.

Standard sheet metal ducting can be attached to the sleave Connector at this time.

\subsection{Closing Up}

closing up consists of installing insulation and flashing between the collectors and around the perimeter of the collector subsystem. Fesco board insulation is recommended in $3 / 4 " \times 2 \frac{1}{2} " \times 48 "$ strips to insulate between the sides of the collectors. This insulation is covered with 1:". plastic U-channel that is screwed down about every

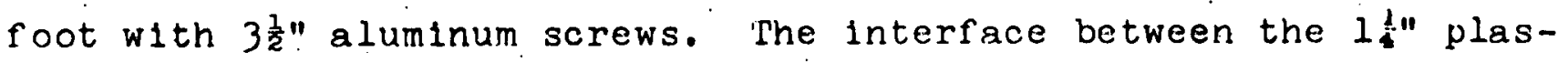
tic U-channel and the H-Bar should be carefully caulked: The plastic U-channel legs fit into the $H$-Har channel and this area is cauiked before the screws are tightened.

The outer perlineter of the Collector Subsystem must be enclosed with insulation. Fesco board 4" Face Cant Strips are recominended 
to gradually slope the roof to the collectors. Standard commerclat aluminum flashing 19 ar 20 gage is recominencled to cover the insulation in accordance with standard practice, Hecominended. flashings include 'Preinline, ALCOA and Johns-Manville.

2. Operations

2.1 Introduction

The Solar II Air Flat plate collector is designed to be compatible with current and future solar heating systens. It is capable of accepting air. flows at various rates for different operational modes.

Solar energy passes through 2 glazing layers on the front of the collector and strikes the flat black coating on the absorber pane1. The coating is designed to absorb most of the incident solar raliation. The glazings prevent motion of alr called convection currents, across the surface of the absorber. Convection currents are the primary" heat loss mechanism. Energy absorbed by the coating is transferred through the aluminum panel by means of conduction or molecular vibrations. To enhance the transfer of energy to the Inoving air stream behind the absorber, the back side of the pariel is painted black. The air stream extracts heat from the absorber. in 2. ways. The primary mechanism is due to the forced air convection across the back of the absorber: The secondary effect is the emission of radiant energy, (Infra-red radiation) which is emitted by any body that is hotter than its surroundings. Some of this radiation is absorbed directly by the air and some is absorbed by the uack panel and transferred to the air by convection.

Solar II was designed for a $50^{\circ} \mathrm{F}$ increase in air outlet temperature 
which is a nominal $320^{\circ} \mathrm{F}$ temperature into the hoine. This temperature was considered safe for the outlet air to heat the house Lirectly. However above $1400 \mathrm{~F}$ outlet alr temperature from the collector, this energy should go to storage only. virecting. and controlling air flow must be regulated by a control subsystem. While Life Sciences ingineering is developing a control subsystem, there are several control systems avallable on the market.

\subsection{Operational l'heckout.}

After the collector has been. Installed and connected to the duct1ng, this system should be checked with the other parts of the heating system. In operation, the collector was designed.for an alr flow of $120 \mathrm{CF}$ although other air flow rates can be used such as $240 \mathrm{CFM}$. The blower motor*air flow should be measured at the collectors at 120CFM each. The pressure drop across the collector should not be more than 1 inch of water. If the pressure drop is greater than i inch of water, there is a blockage which should be removed.

When collecting heat to heat the home directly, the outlet temperature of the collectior should not be more than $140^{\circ} \mathrm{F}$ for an inlet temperature of $70^{\circ} \mathrm{F}$. If temperatures over $140^{\circ} \mathrm{F}$ are found for the $70^{\circ} \mathrm{F}$ inlet air., the blower motor should be increased in speed unt1l the outlet air temperature is less than $140^{\circ} \mathrm{F}$. This condition is unlikely but should be checked. Outlet air temperatures above litu ${ }^{\circ} \mathrm{F}$ should go to storage only.

* Solar heating systeins have blower motors separate from the regular home heating system or backup systein. The blower motor for the solar heating subsystem usually operates in series with the regular heating system blower. 
When collecting heat for storage, the temperature of the outlet alrwill of ten be much higher than when heating air for the home directly. For a $140^{\circ} \mathrm{F}$ inlet air temperature, an outlet air temperature of $172^{\circ} \mathrm{F}$ can be expected. In this increase $1 \mathrm{~s}$ not being achieved, the control system requires adjustinent to attain this temperature change.

3. Maintenance.

Introduction

Maintenance consists of two parts, periodic maintenance and repair maintenance.

3.1 Periodic Maintenance

Periodic maintenance consists of occasional inspections for problems such at tears in the Tedlar or cracks in the glass. Inspection should include checks for water leakage, especiolly at the caulking interfaces. Inspections are recominended once per month. vuring long duration dry spells, the outer glazing should be washed with water or sprayed with a hose on the average of once per month under these conditions. If the Tedlar. is very dirty, a mild soap may be used to wash down the Tedlark.

\subsection{Repair Maintenance}

Repair maintenance consists of mincr and major repairs.

\subsubsection{Minor Repairs}

Ted lar ${ }^{\mathrm{H}}$ punctures should be repaired as soon as noticed. kepair consists of applying a small dab. of lie silicone glue and sal. A Tellar ${ }^{\mathrm{H}}$ repair kit of 2 mil. Tedlar is also avallable with adhesive already attached to the $2 \mathrm{mil}$ redlar 
If a leak is noticed, Inspect all caulking, especialiy the interfaces. Caulk these cracks and lest with a spray of water. Spray-: ing one sinall section at a time will lsolate the leak area.

\section{$3.2: 2$ Major Repairs}

3.2 .2 .1 Tediar, Repair

Major Tedlar tears require replacement of the entire glazing at ground level. Remove the Tedlar by removing the plastic spline and pull/cut out the Tedlar in the H-Bar channel. Clean out the H-Bar channel with a mixture of isopropenol-trichloroethylene. Insert a 1/8" bead of Gelva 1752 into the H-Bar channels. Brush the Gelva into a thin coating $(1 \mathrm{mll})$ on each side. Allow the Gelva to alr dry for a minimum of 15 minutes." Extend the new 'Tedlar a minimum of $\frac{1}{2}$ " beyond the H-Bar egges. With an assistant holding one end of the rediar taut, and the installer holding the other end taut, the. convex wheel of the screening wheel is used to force the redlar into the H-Bar channel. Start in the middle of one slde as shown in Fl. lire 1. By keeping the ends taut over the U-channel, the l'edlar will go in smoothly, and uniformly taut. Next insert the .145" plastic spline into the Tedlar/H-Bar channel. Use the concave wheel to install $8^{\prime}$ of spline. When one side is completed, install the 'Tedlar In the opposite side, followed by the $8^{\prime}$ length of spline. Repeat this procedure for the 2 reinaining ends. The redlar corners require a bias out to fit properly whioh should be completed after the Tedlar is installed in all 4 channels. The spline is also cut on a $45^{\circ}$ bias and pressed down in each corner with a $1 / 8$ " flat bar. Place the redlar fraine back on the collector by carefully fitting the corners. Settjng the collector with the redlar frame attached in the sun until the redlar reaches $150^{\circ} \mathrm{F}$ will shrink the redlar when put in a cool location immediately. 
SECOND INSERT TEDLAR IN OTHITR LONG SIDE AF TER IIISEI T7M $\mathrm{A}$ GE METALIC SILICONIE GLIJE \&' SEAL.

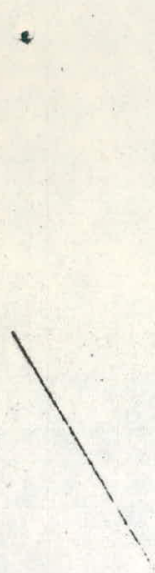

$$
\text { PLASTIC ' } 1 / 8^{1}
$$$$
\text { SPLINE }
$$

$+$

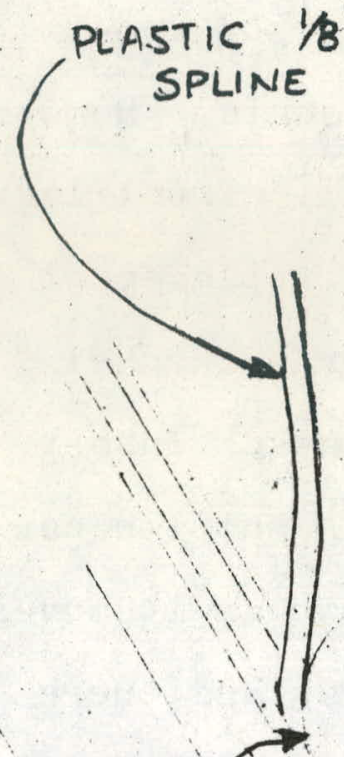

SCREENING

START EY INSERTIIG

TEDLAR IN

CENIEO OI OMI

LOHG SITE.

GE MET/LLIC SILICONE GLUE द' SEAL INSERTED IN $1 /$ " $^{\prime \prime}$ SLOT

* tedlar OVERHANG

, $\mathrm{A}: 1 / 2$ " ON STARTIME SIDE

H-PAR INSTALLED ON MAIN FFAME

PNUNET COFMERS
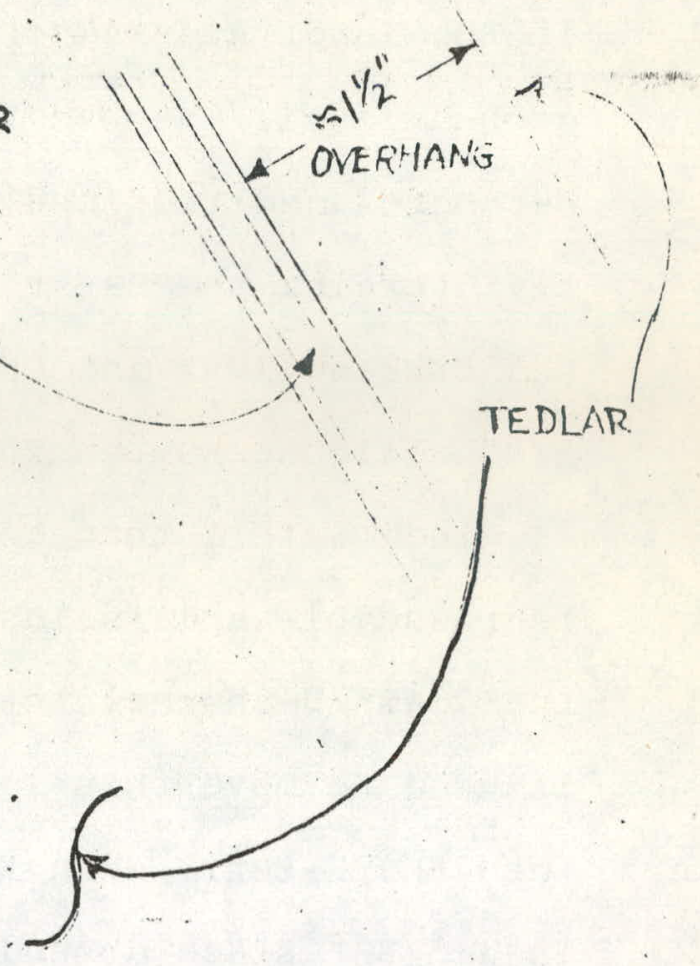
If the inner 6 lazing of grlass breaks, repair should be made at

grround level. Kemove the fedlar:frame by taking of the plastic U-channel and the insulation. 'lhe l'edlar frane is removed by gently forcing the $H-b a r U_{p}$ with a $1 / 8 "$ plece of aluminum angle. Remove the broken glass and Low Corninks 732. silicone rubber seal. The 1/16"x 5/8" silicone rubber strip may have to be replaced. The replacement is glued with a thin coating of 732. The silicone rubber U-channel is reuseable and is installed on the $46 \frac{1}{3} "$ side of the girass. Insert the glass/U-channel into the $\mathrm{H}$-Bar on the support bar. A suction cup is used to move this leading edge of the glass up and down as it moves into the H-Bar. When the glass fits snugly into the H-Bar and there is a $5 / 32^{\prime \prime}$ space around 3 sides, move the suction cup to the opposite edgre of the glass and gently lower the glass onto the silicone rubber strip. After checking all 3 sides for the $5 / 32$ " spacing, insert now Corning 732 into this spacing and allow to cure for a minimum of 1 hour. A second bead of 732 is placed over the Last 3/32" of धlass and over to the collector edges. Allow to cure in the sun or at room temperatures for several hours, preferably 8 hours for the 732 to outgas and harden. It is recommended that the collector be installed before replacing the redlar fraine. ' Replacement of the redlar f'rame consists of fitting the corners of the frame over the collector and then yently tapplng the frame in place with a rubber mallet.

Blass may often contain markinfs in crayon from the manufacturex. These markings can be reinoved with a wet cloth and Bon Ainl. Isopropyl alcohol will remove fingerprints for final cleanup. 
- In the event of a paint repair problem; which is not expected for a minimum of 10 years, repainting should be done at ground level. The collector must be removed from the roof and disassembled by removing the Tedlar ${ }^{\mathrm{K}}$ frame and tempered glass. A complete absorber pañel repainting should be done in a paint shop which has the proper equipment.: 'The old paint should be removed with paint remover." The panel is then cleaned with $x y$ lene. In should be refinished with chromic acid. An undercoat of a wash primer such as Sherman Williams which is mixed with their Catalyst Reducer and sprayed on to a thickness of 0.25 to 0.35 mils. After the wash primer has dried for $\frac{1}{2}$ hour, the Nextel paint is sprayed on to a thickness of 1 to 3 inils. Nextel may be thinned with up to 10\% xylene. After spraying, allow to dry for 1 to 2 ininutes and then bake in an oven at $250^{\circ} \mathrm{F}$ for $\frac{1}{2}$ hour. If an oven is not avallable, place the collector in full sunlight; cover with a plastic sheet and allow to bake in the sun for several hours with a plastic heet covering it. Solar baking should reach a mintmum of $225^{\circ} \mathrm{F}$ in a closed container for several hours around solar noon. It may be necessary to insulate around the collector to reach this temperature. Baking permits the new paint to outgas which may collect on the Inexpensive plastic shect. After baking, the collector must be reassembled. It may be necessary to replace the silicone rubber strips that cover the U-channel that supports the glass. Glass replacement is described in paragraph 3.2.2.2. Be sure to keep the collector free of dust and dirt, etc.

Minor scratcines can be repaired Nextel paint.

with a paint brush or a spray can of 
MATERIAL LIST AND INSTALLATION CONCEPTS

DRAW ING NO. SC4X8106 


\section{LISIT OF MATEKIALS}

Glass - Sunadex tempered glass, ASG Industries, size $46 \frac{1}{2} " x 47-5 / 16 "$ $x 5 / 32$ " or equivalent low iron glass (approx. .01\% iron).

Plastic U-Chapnel - Iife sciences Engineering, size $1 \frac{1}{1} \times 1 / 8^{\prime \prime} \times 12^{\prime}$ of Nory ${ }^{R}$ : plastic or equivalent.

Paint - 3M Nextel ${ }^{\mathrm{H}}$ Black, (Black Velvet) 101-Cio or equivalent.

Primer - Sherwin-Williams P60G2 with W/K7K44 Catalyst or equivalent.

Adhesive - Now Corning RTV 732 silicone rubber or equivalent.

redlar ${ }^{\mathrm{K}}$ - iu Pont, $4 \mathrm{mil}, 400 \times \mathrm{BR} 160-50 "$, or equivalent.

Spline, plastic - Anson .145 diameter or equivalent.

Side Insulation - Johns-Manville Fesco Board 3/4n, R value 4.17 or equivalent insulation:

Perimeter. Insulation.- Johns-Manville Fesco Cant Strips or equivalent onsulation with 4" diagonal facing. Also use sicie insulation.

Back Insulation - Poly-Urethane board, $R$ value 9 or better, OwensCorning or equivalent. .

Tedlar Adhesive - Gelva 1753. Monsanto or equivalent

Tedlar Repair Adhesive - General Electric Silicone ilue and Seal

Silicone kubber strip - 1/16"x5/8", Kubbercraft 


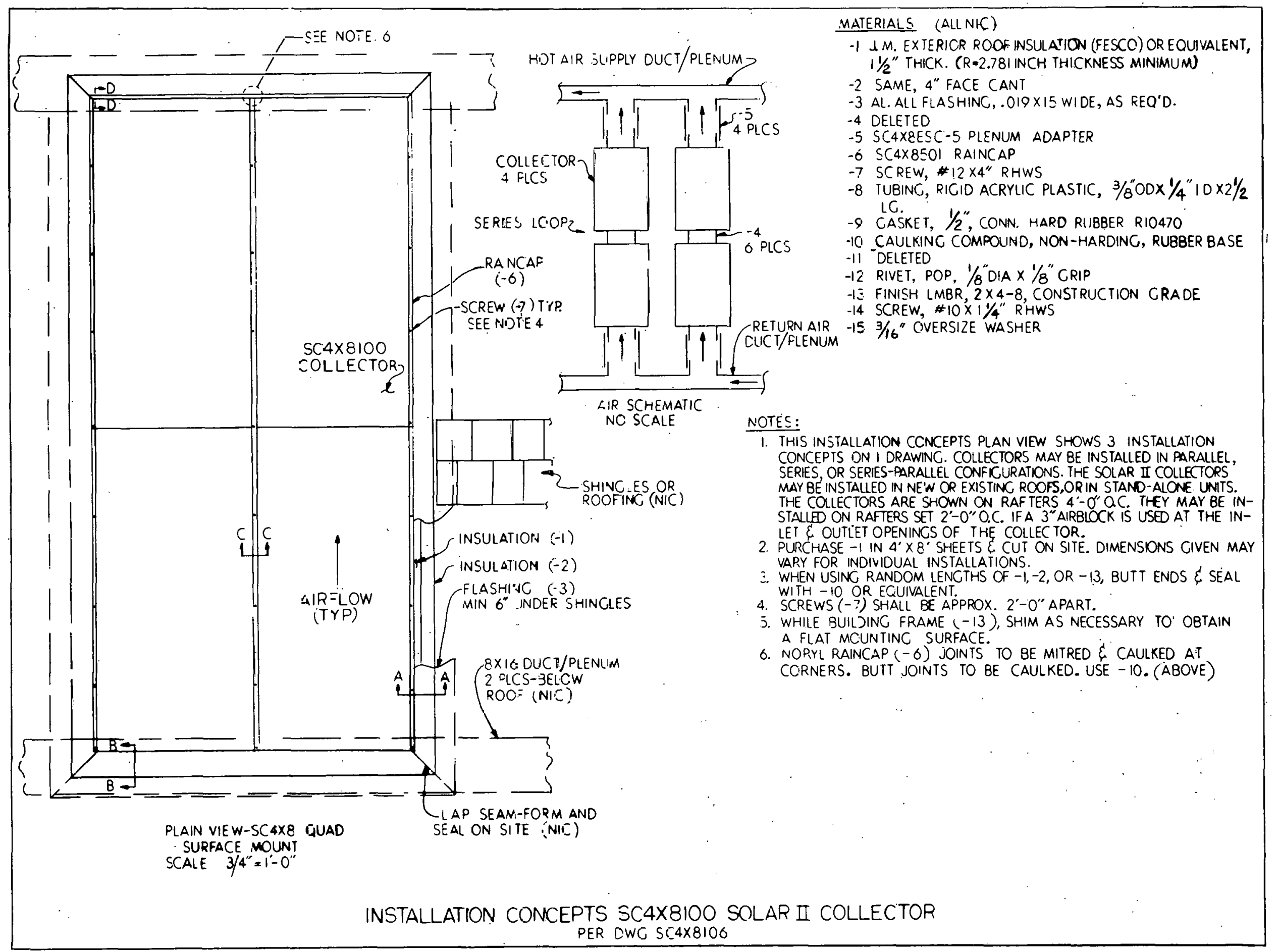




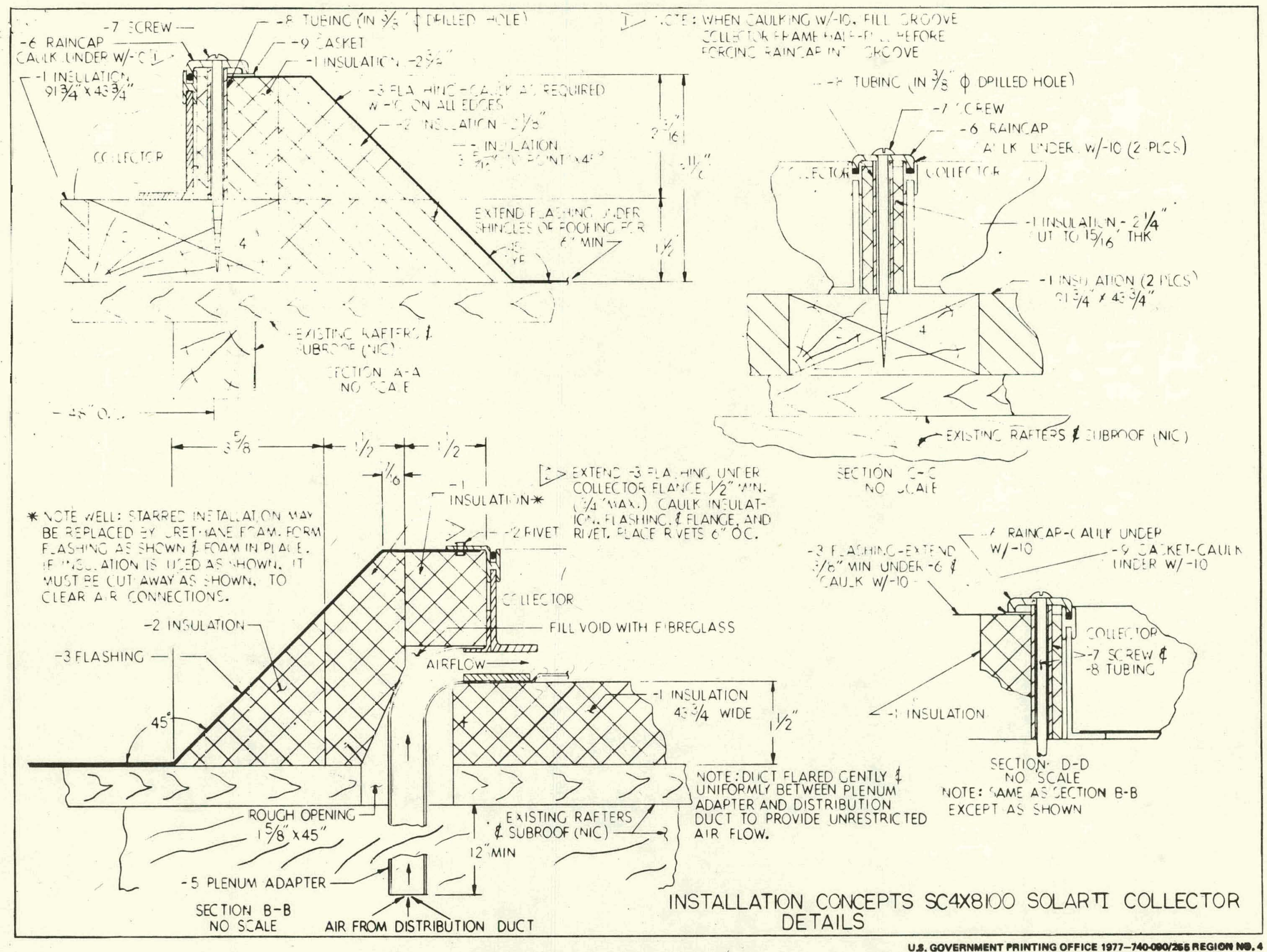

